\title{
Illness Perception in Gestational Trophoblastic Disease Patients: How Mental Representations Affect Anxiety, Depression, and Infertility-Related Stress
}

\author{
Letizia Carnelli'1,2, Valentina E. Di Mattei1,2, Martina Mazzetti1, Martina Bernardi', Rossella Di Pierro ${ }^{3}$, \\ Alice Bergamini ${ }^{4}$, Francesca Pella4, Giorgia Mangili' ${ }^{4}$, Lucio Sarno ${ }^{1,2}$, Massimo Candiani ${ }^{1,4}$
}

${ }^{1}$ Vita-Salute San Raffaele University, Milan, Italy

${ }^{2}$ Clinical and Health Psychology Unit, IRCCS San Raffaele Hospital, Milan, Italy

${ }^{3}$ Department of Psychology, University of Milano-Bicocca, Milan, Italy

${ }^{4}$ Obstetrics and Gynecology Unit, IRCCS San Raffaele Hospital, Milan, Italy

Email: carnelli.letizia@hsr.it

How to cite this paper: Carnelli, L., Di Mattei, V.E., Mazzetti, M., Bernardi, M., Di Pierro, R., Bergamini, A., Pella, F., Mangili, G., Sarno, L. and Candiani, M. (2017) Illness Perception in Gestational Trophoblastic Disease Patients: How Mental Representations Affect Anxiety, Depression, and Infertility-Related Stress. Open Journal of Medical Psychology, 6, 1-15.

http://dx.doi.org/10.4236/ojmp.2017.61001

Received: September 29, 2016

Accepted: December 4, 2016

Published: December 7, 2016

Copyright (c) 2017 by authors and Scientific Research Publishing Inc. This work is licensed under the Creative Commons Attribution International License (CC BY 4.0).

http://creativecommons.org/licenses/by/4.0/

cc) (i) Open Access

\begin{abstract}
Gestational Trophoblastic Disease encompasses a group of pregnancy-related disorders that derive from the placenta. Taking Leventhal's Common Sense Model as a starting point, this study aims to investigate how illness perception could influence patients' psychological adaptation to these rare diseases. Thirty-seven women completed: the Illness Perception Questionnaire-Revised, the Beck Depression Inventory Short Form, the State-Trait Anxiety Inventory, and the Fertility Problem Inventory. Results show that the perception of severe illness consequences significantly predicts the level of anxiety patients reported at the time of questionnaire completion. Furthermore, mental representations of illness present a significant association with infertility-related stress. Specifically, the belief in the efficacy of the treatment results in fewer feelings of discomfort and isolation from family and social context due to infertility-related problems. Since patients' illness perception was found to have a specific impact on both anxiety and infertility-related stress, this variable should be considered in the planning of a clinical intervention.
\end{abstract}

\section{Keywords}

Gestational Trophoblastic Disease, Illness Perception, Anxiety, Depression, Infertility-Related Stress

\section{Introduction}

Gestational Trophoblastic Disease (GTD) encompasses a group of pregnancy-related 
disorders that derive from the placenta. These include the premalignant complete and partial molar pregnancies, also known as hydatidiform mole (HM), the malignant invasive mole (IM), choriocarcinoma (CCA), placental site trophoblastic tumor (PSTT), and epithelioid trophoblastic tumor (ETT) [1]. The malignant conditions are known as gestational trophoblastic neoplasia (GTN).

The incidence of hydatidiform mole is varied, ranging from 1.5 to 6 per 1000 pregnancies in North America, Europe, and Southeast Asia. In Italy specifically, the estimated frequency of HM is 1 case every 935 pregnancies [2]. In Europe and North America, CCA affects approximately 1 in 40,000 pregnancies, while for PSTT the incidence is estimated at $0.2 \%$ of all GTD; ETT is a relatively new entity and data regarding its epidemiology are scarce [1].

Although previously a lethal disease, GTD is presently considered one of the most curable gynecological cancers. Appropriate chemotherapy and surgery result in excellent survival rates (>90\%), even in the presence of metastases. Moreover, patients with a history of molar pregnancy or GTN can generally anticipate normal future reproductive outcomes [3].

Treatment depends on the individual patient, the type of tumor, and the absence/ presence of metastases. Hydatidiform moles are removed by suction and curettage, followed by $\beta$-hCG (beta subunit of human chorionic gonadotropin) surveillance for at least 6 months. GTN is usually treated with chemotherapy. After chemotherapy, the $\beta$-hCG follow-up goes on for at least 1 year. In the case of chemotherapy-insensitive PSTT, hysterectomy may be the only course of action [1]. During follow-up, contraception is recommended: this is to distinguish a rising $\beta$-hCG due to persistent or re-current disease from a rising $\beta$-hCG associated with a subsequent pregnancy [4].

GTD diagnosis, treatment and follow-up represent a sudden and prolonged factor of stress, which forces the patient and her partner to find a new psychological accommodation [5]. This psychological distress is anticipated and understandable when the patient and her partner discover that their pregnancy is considered potentially cancerous. Although a cure is generally anticipated, inherent psychosocial stressors exist. These include: a loss of a pregnancy, surgery or chemotherapy, a potentially life-threatening diagnosis, and delay in future pregnancy while waiting for $\beta$-hCG levels to normalize [6]. This unique set of circumstances has led to the investigation of the psychosocial impact of GTD [7] [8] [9].

Several theories and models have highlighted how patients' beliefs and perceptions of their disease and symptoms are important factors for psychological adjustment to their condition [10] [11]. The Common-Sense Model (CSM) of Illness Representation, proposed by Leventhal, Meyer \& Nerenz [12], hypothesizes that people make sense of their illness and manage it by developing their own cognitive representations, on the basis of information and previous experiences. According to this model, a response to a health threat depends on a basic control system, which can be divided into three comprehensive processes. The first is the construction of a representation of the disease. This representation is assumed to be based on three sources of information: general "lay" information that an individual has previously assimilated, knowledge from friends, family, and authoritative sources, and the current experience of the illness (such as somatic 
experiences and symptoms) [13]. The second stage involves the development of a plan of action in which individuals use coping strategies they believe to be appropriate. The third phase is the process of coping appraisal, which consists in the evaluation of the coping strategies' effectiveness on the outcome. The CSM assumes that these three stages occur in parallel on both an emotional and cognitive level, and it underscores that the interaction between each level is dynamic, so that each component is influenced by a process of feedback [14].

The cognitive representations or illness perceptions are formulated around the following dimensions: identity (the label given to the condition and the symptoms the patient perceives to be related to his/her illness), cause (beliefs regarding the factors that are responsible for causing the illness or disease, which may not be completely biomedically accurate), timeline (the individual's belief about the course of the illness and time scale of illness symptoms), control (belief about the cure or controllability of an illness), consequences (the individual beliefs about the outcomes of the condition), and emotional representations (the emotional responses generated by the illness) [15]. The relationship between illness perception and psychological morbidity has never been analyzed in GTD patients; to our knowledge, illness representations have been investigated in this group of patients exclusively in relation to medical and demographic variables [16]. Using this literature as a starting point, we designed an explorative study with the aim of evaluating how patients perceive their illness during the $\beta$-hCG follow-up period after GTD diagnosis. Our main goal was to evaluate how mental illness representations could influence patients' psychological adaptation to Gestational Trophoblastic Disease. Specifically, we aimed to assess if illness perception predicted the level of anxiety, depression, and perceived infertility-related stress reported by women who had been diagnosed with GTD. The overall aim of the study was to explore mental illness representations in patients diagnosed with these rare trophoblastic tumors in order to provide support to these women in an outpatient clinical setting.

\section{Materials and Methods}

\subsection{Sample Selection and Recruitment}

Patients treated for GTD at a Hospital in Northern Italy were invited to take part in the study. Women were recruited in the outpatient Gestational Trophoblastic Hospital Clinic; no patient declined to take part in the study. Eligible women had to be Italianspeaking, with at least an elementary school certificate and agreed voluntarily to participate in the study. Based on these criteria 37 women were included in the research $(\mathrm{N}$ = 37). Twelve women were diagnosed with GTN and the other 25 patients had premalignant forms of GTD (partial or complete hydatidiform mole). The age range of our sample was from 18 to 56 years (mean age $=36.43$; $\mathrm{SD}=9.368$ ). The study was approved by the Hospital Medical Ethical Committee on May 6th, 2010. Written informed consent was obtained from each participant during questionnaire completion.

\subsection{Measures}

Socio-demographic and clinical information was collected via a self-report questionnaire that included: type of treatment, diagnosis, date of diagnosis, parity, education 
level, date of birth, and marital status.

In order to analyze illness perceptions in our sample, the Illness Perception Questionnaire-Revised (IPQ-R) was administered [17] [18]. This questionnaire is divided into three parts. The first is the Identity scale (14 items), which measures the number of symptoms patients have experienced and whether they perceive these symptoms as pertaining to their illness (yes-1; no-0). The other two sections are measured on a 5-point Likert scale (from 1 "strongly disagree" to 5 "strongly agree"). The second part investigates patients' opinions with respect to their illness via 38 items which are divided into: Timeline acute-chronic, Timeline cyclical, Personal control, Treatment control, Illness coherence, and Emotional representations (see Table 1 for details). Finally, the third part investigates the explanations patients give as reasons for their illness (Causes subscale) and this is further divided into 3 sections: stress or worry, hereditary causes, and chance or bad luck [11] [18]. Cronbach's alpha reliability scores for the Italian version of the test were in the range of $0.50-0.82$.

The Beck Depression Inventory (BDI) is one of the most widely used self-rating scales for measuring depression [19]. It is composed of two subscales that measure cognitiveaffective and somatic symptoms of depression, respectively [20]. For the purpose of the present study, the Italian version of the 13-item cognitive-affective subscale (BDI-SF) was administered [21]. Each question has a set of 4 possible responses, ranging in intensity (from 0 to 3 ); a cut-off score of 9 is suggested to detect moderate to severe depression in medically-ill patients [22]. In the Italian version, the cognitive-affective subscales show good internal consistency reliability ( $\alpha$ range $=0.75-0.95)$ [23].

The State-Trait Anxiety Inventory (STAI) is a widely used measure of state and trait anxiety [24] [25]. This questionnaire has been used extensively in clinical contexts, including the assessment of anxiety in cancer patients [26] [27]. It consists of two subscales each one composed of 20 items: the state subscale measures anxiety related to a specific situation or time-period (at the moment of questionnaire completion), while the trait one measures relatively stable anxiety (how one feels on a day-to-day-basis). For the purpose of this study, only the state anxiety scale was used. Responses are given on a 4-point Likert scale (from 1 "not at all" to 4 "very much so"). Total scores range from 20 to 80 for each subscale; in order to provide clinical meaning, scores are grouped into three categories: low anxiety (scores of 20-39), medium anxiety (scores of 40 - 59), and high anxiety (scores of 60-80). In the Italian version the state anxiety scale [24] showed excellent internal consistency reliability ( $\alpha$ range $=0.91-0.95$ ).

Table 1. The second section of the IPQ-R questionnaire; its components and what they examine.

\begin{tabular}{cc}
\hline Component & Measures \\
\hline $\begin{array}{c}\text { Timeline acute-chronic } \\
\text { Timeline cyclical } \\
\text { Personal control }\end{array}$ & How long patients believe their illness will last \\
Treatment control & How one recovers from or controls the illness \\
Illness coherence & Beliefs regarding treatment efficacy \\
Emotional representations & Whether there is a coherent understanding of the condition
\end{tabular}


The Fertility Problem Inventory (FPI) is a 46-item measure of perceived infertilityrelated stress [28] [29]. Items are rated using a Likert-type format, ranging from 0 (strongly disagree) to 6 (strongly agree). The FPI provides information on five separate domains of patients' concern: Social concern (i.e., feelings of discomfort and social isolation from one's family and others due to infertility-related problems), Sexual concern (i.e., a perceived reduction of pleasure and self-esteem concerning one's sexual life), Relationship concern (i.e., difficulty in speaking about infertility with one's partner and issues regarding its impact on the relationship), Need for parenthood (i.e., perception of parenthood as a fundamental target in life and strong identification with the parental role), and Rejection of child-free lifestyle (i.e., the perception that personal future satisfaction and happiness will rest on having a child). A composite measure of Global stress is also derived by summing the scores of all five scales [30]; for women, mean scores greater than 27 indicate high levels of infertility stress (Newton et al., 1999). The Cronbach's alpha reliability scores of the Italian version are in the range of 0.77 - 0.93 [28].

\subsection{Statistical Analysis}

Statistical analyses were conducted using SPSS software, version 22.0 [31].

Correlations between illness perception dimensions, levels of anxiety, depression, and perceived infertility-related stress were evaluated by virtue of the Spearman's correlation coefficient $\rho$. Considering the correlational analysis results, multiple linear regression analyses were conducted to study the relationships between illness perception, psychopathological variables, and dimensions of infertility-related stress. These analyses were conducted controlling for age, time since diagnosis, and type of diagnosis, since these factors could interfere with the relationship between illness perception, psychopathological symptoms, and infertility-related stress in patients with GTD.

\section{Results}

\subsection{Sample Characteristics}

The majority of women in our sample $(81.1 \% ; \mathrm{N}=30)$ were married, $8.1 \%(\mathrm{~N}=3)$ were single and $10.8 \%(\mathrm{~N}=4)$ were living with their partner. Ninety-five per cent of the sample declared that at the moment of questionnaire completion they were in a stable relationship. In our sample $59.5 \%(\mathrm{~N}=22)$ of the women had had a child prior to the GTD diagnosis, whereas for $40.5 \%(\mathrm{~N}=15)$ women this was their first pregnancy. Of the women who had already had a child $43.2 \%$ had only previously had one child, whereas $16.3 \%$ had given birth to two children prior to the disease diagnosis. No patient declared to have had a child after GTD as all the women in our sample took part in the study during the $\beta$-hCG follow-up period. With regard to the disease variables, most of the patients in our sample were suffering from partial or complete hydatidiform mole $(67.6 \% ; \mathrm{N}=25)$. The remaining women $(32.4 \% ; \mathrm{N}=12)$ were diagnosed with gestational trophoblastic neoplasia (GTN), which included invasive mole, choriocarcinoma, and placental site trophoblastic tumor (PSTT). The mean time elapsed from diagnosis to questionnaire completion was 4 months (range $=0-25 ; \mathrm{SD}=4.503$ ). All patients with GTN were treated with chemotherapy except for three women who underwent to- 
tal hysterectomy. Women with HM diagnosis were undertaking only gonadotropin ( $\beta$-hCG) follow-up.

\subsection{Illness Perception Results}

Means, standard deviations and IPQ-R scale ranges are reported in Table 2. As shown, participants scored relatively high on dimensions of treatment control and emotional representations, suggesting that women have positive beliefs about the treatment's efficacy, but also strong emotional responses generated by the illness. Moreover, participants scored relatively low on dimensions of identity and timeline cyclical. These findings suggest that women tend to perceive GTD as a condition characterized by a relatively restrained symptomatology, and that GTD is not perceived as cyclical in nature.

With respect to the causes of GTD, patients' opinions are reported in Table 3. Specifically, within the psychological attributions subscale, the highest mean score was reported on the "stress/worry" causal factor (mean $=2.68$; $\mathrm{SD}=1.41$ ). Within the Risk factors subscale, the highest mean score was reported on the "ageing" causal factor (mean $=2.49 ; \mathrm{SD}=1.17$ ). Within the Immunity subscale, the highest mean score was reported on the "pollution in the environment" item (mean $=2.54$; $\mathrm{SD}=1.12$ ) and within the Accident/chance subscale, the highest mean score was the "chance/bad luck" causal factor (mean $=3.92$; $\mathrm{SD}=1.21$ ). Considering each possible cause singularly, the highest mean score was on the chance/bad luck causal factor dimension.

Table 2. Means, standard deviations, ranges, minimum and maximum scores of the IPQ-R "Identity" and "Illness opinions" subscales.

\begin{tabular}{ccccc}
\hline IPQ-R subscales & Range & M (SD) & Min. & Max. \\
\hline Identity & $0-14$ & $2.89(2.50)$ & 0 & 9 \\
Timeline acute/chronic & $6-30$ & $12.81(3.33)$ & 6 & 21 \\
Timeline cyclical & $4-20$ & $9.54(3.24)$ & 4 & 16 \\
Consequences & $6-30$ & $17.00(3.80)$ & 10 & 26 \\
Personal control & $6-30$ & $16.41(4.71)$ & 6 & 30 \\
Treatment control & $5-25$ & $19.76(2.83)$ & 13 & 25 \\
Illness coherence & $5-25$ & $17.16(3.83)$ & 9 & 25 \\
Emotional representations & $6-30$ & $20.46(4.66)$ & 10 & 30 \\
\hline
\end{tabular}

Table 3. Means, standard deviations, ranges, minimum and maximum scores of the IPQ-R "causes" subscale.

\begin{tabular}{ccccc}
\hline IPQ-R subscales & Range & M (SD) & Min. & Max. \\
\hline Psychological attributions & $6-30$ & $12.19(5.18)$ & 6 & 24 \\
Risk factors & $7-35$ & $13.43(4.04)$ & 7 & 23 \\
Immunity & $3-15$ & $6.70(2.62)$ & 3 & 14 \\
Accident or chance & $2-10$ & $5.43(1.40)$ & 2 & 8 \\
\hline
\end{tabular}




\subsection{Depression, Anxiety and Infertility-Related Stress}

Means and standard deviations on the BDI and STAI are reported in Table 4. The mean score on the Beck Depression Inventory was 4.95 ( $\mathrm{SD}=4.24)$, which does not indicate a clinically significant level of depression. However, 7 of our 37 women (18.9\%) showed levels of depression that can be considered severe $(\geq 9)$ (Table 3 ).

With respect to anxiety, on the state subscale of the STAI questionnaire patients reported a mean score of 47.19 ( $\mathrm{SD}=12.52$ ). Both scores fall within the medium anxiety range of the STAI questionnaire (scores $40-59$ ). Only 6 patients (12.9\%) presented high levels of state anxiety (scores $\geq 60$ ) (Table 3 ).

With regard to infertility related stress, means and standard deviations are reported in Table 5. The Global stress mean score (mean $=14, \mathrm{SD}=3.05$ ) was not of clinical significance (the clinical significance is set between 27 and 30); considering each dimension of the FPI singularly, the highest mean scores were found in two different subscales regarding patients' infertility concerns: Need for parenthood (mean $=3.93$, $\mathrm{SD}=1.04)$ and Rejection of child-free lifestyle (mean $=3.55, \mathrm{SD}=1.03)$.

\subsection{Correlation Analysis}

Several significant correlations emerged from the analysis of the IPQ-R subscales and the psychopathological variables. Specifically, the Timeline acute/chronic $(\rho=.40, p<$ $0.05)$, Consequences $(\rho=0.43, p<0.05)$, and Emotional representation subscales ( $\rho$ $=.35, p<0.05)$ of the IPQ-R were positively associated with state anxiety. Moreover, the Illness coherence subscale of the IPQ-R was negatively correlated with state anxiety $(\rho=-0.41, p<0.05)$.

With regard to correlations between the mental representation of illness and infertility-related stress, a positive correlation emerged between the Consequences IPQ- $R$

Table 4. Means, standard deviations, ranges, minimum and maximum scores of the BDI-SF and of the STAI.

\begin{tabular}{ccccc}
\hline & Range & M (SD) & Min. & Max. \\
\hline BDI-SF Total Score & $0-39$ & $4.95(4.24)$ & 0 & 16 \\
STAI State & $20-80$ & $47.19(12.52)$ & 24 & 76 \\
STAI Trait & $20-80$ & $40.68(9.46)$ & 25 & 63 \\
\hline
\end{tabular}

Table 5. Means, standard deviations, ranges, minimum and maximum scores of the FPI subscales.

\begin{tabular}{ccccc}
\hline & Range & M (SD) & Min. & Max. \\
\hline Social concern & $0-6$ & $2.10(0.74)$ & 1 & 5 \\
Sexual concern & $0-6$ & $2.25(0.85)$ & 1 & 5 \\
Relationship concern & $0-6$ & $2.21(0.85)$ & 1 & 5 \\
Need for parenthood & $0-6$ & $3.93(1.04)$ & 1 & 6 \\
Rejection of child-free lifestyle & $0-6$ & $3.55(1.03)$ & 2 & 6 \\
Global stress & $0-30$ & $14.00(3.05)$ & 7 & 21 \\
\hline
\end{tabular}


subscale and the Sexual concern subscale of the FPI questionnaire $(\rho=.40, p<0.05)$. Treatment control correlated negatively with Social concern $(\rho=-0.36, p<0.05)$. Moreover, a positive correlation emerged between the Consequences IPQ- $\mathrm{R}$ subscale and relational concerns $(\rho=0.35, p<0.05)$.

No significant correlations were found between depression and the IPQ-R subscales.

\subsection{Regression Analysis}

With respect to the relationship between illness perception and state anxiety, regression analyses revealed that only the Consequences subscale was significantly associated with the state anxiety subscale $(\beta=0.39, \mathrm{t}(29)=2.17, p<0.05)$ after controlling for age, time since diagnosis, and type of diagnosis (Table 6). The more a patient believed the illness was severe, the higher the level of state anxiety reported in our sample at questionnaire completion.

Regarding the links between illness perception and infertility-related stress dimensions (Table 7), results show that only the Treatment control subscale maintained a significant relationship with the Social concern subscale $(\beta=-0.40, \mathrm{t}(32)=-2.35, p<$ 0.05 ) after controlling for age, time since diagnosis, and type of diagnosis. The greater confidence in the treatment effectiveness the lower social concern.

\section{Discussion}

Women diagnosed with hydatidiform mole or GTN generally have very good prognoses [6]. Despite the fact that a full recovery is generally expected, women diagnosed with GTD have to face the loss of a pregnancy, a potentially life-threatening diagnosis, surgical and/or chemotherapy treatment, and delays in future pregnancies [32]. Thus, a wide range of psychosocial stressors are elicited by this disease. GTD diagnosis consequently

Table 6. Multiple linear regression analysis: state anxiety.

\begin{tabular}{|c|c|c|c|c|c|}
\hline & \multicolumn{5}{|c|}{ STAI STATE } \\
\hline & $\beta$ & $\mathbf{t}$ & $\mathbf{R}^{2}$ & df & $\mathrm{F}$ \\
\hline Regression model 1 & & & 0.15 & 3 & 1.91 \\
\hline Age & 0.33 & 2.03 & & & \\
\hline Time since diagnosis & -0.17 & -1.07 & & & \\
\hline Diagnosis & 0.09 & 0.58 & & & \\
\hline Regression model 2 & & & $0.46^{\mathrm{a}}$ & 7 & 3.61 \\
\hline Consequences & $0.43^{\mathrm{a}}$ & 2.43 & & & \\
\hline Timeline acute/chronic & -0.19 & -1.11 & & & \\
\hline Illness coherence & -0.30 & -1.79 & & & \\
\hline Emotional representations & 0.21 & 1.23 & & & \\
\hline Age & 0.17 & 1.19 & & & \\
\hline Time since diagnosis & -0.14 & -0.85 & & & \\
\hline Diagnosis & -0.18 & -1.14 & & & \\
\hline
\end{tabular}

${ }^{\mathrm{a}} p<0.05$. 
Table 7. Multiple linear regression analysis: social concern.

\begin{tabular}{cccccc}
\hline & \multicolumn{5}{c}{ SOCIAL CONCERN } \\
\cline { 2 - 5 } & $\boldsymbol{\beta}$ & $\mathbf{t}$ & $\mathbf{R}^{2}$ & $\mathrm{df}$ & $\mathbf{F}$ \\
\hline Regression model 1 & & & 0.04 & 3 & 0.49 \\
Age & -0.06 & -0.37 & & \\
Time since diagnosis & -0.06 & 0.36 & & \\
Diagnosis & 0.20 & 1.16 & & \\
Regression model 2 & & & & \\
Treatment control & $-0.40^{\mathrm{a}}$ & -2.35 & & \\
Age & -0.08 & -0.51 & & \\
Time since diagnosis & 0.06 & 0.38 & & \\
Diagnosis & 0.20 & 1.25 & & \\
\hline
\end{tabular}

${ }^{\mathrm{a}} p<0.05$.

poses a considerable challenge to the couple since it entails a sudden shift from feelings of hopefulness and gratitude associated with pregnancy to managing a condition of disease [6]. Even if the psychological impact of this condition for both the patient and her partner is clearly predictable and understandable, clinicians and health care professionals often overlook the psychological distress in GTD and only recently more attention has been paid to the psychological effects of GTD [6]. Specifically, focus has been on the psychopathological consequences of the disease [7] [8], on patient quality of life [9] [33], and on infertility-related stress [7] [8] [9].

The present study has the aim of expanding on previous research in this area to explore the mental representations of illness that women with Gestational Trophoblastic Disease present. In particular, we wanted to examine how illness perception could influence patients' psychological adaptation to GTD, identifying the IPQ-R subscales which significantly predict the level of anxiety, depression, and perceived infertility-related stress reported by women suffering from this group of disorders.

The Common Sense Model has been used with success to explain psychological and physical outcomes in a range of acute and chronic illnesses [10]. There is evidence that the model is useful in predicting psychological well-being in different clinical conditions [34]. In psycho-oncology, one of the first studies that examined this theme was conducted by Millar and colleagues [35]. These authors assessed the individual variation in distress during follow-up after breast cancer and evaluated the salience of illness perception to psychological morbidity. Their results showed that IPQ symptom awareness (Identity) and the perceived timeline of the illness (Timeline acute-chronic), together with the initial state of distress and patients' general health perception, were significant predictors of psychological morbidity during the 1-year follow-up. Gould and colleagues [36] investigated the use of the CSM in predicting mood disturbances in gynecological cancer patients. The authors highlighted how all illness perception dimensions-except for the "Timeline acute-chronic" subscale-showed a significant relationship with the scores patients obtained on the Profile of Mood States-Short Form which assesses transient and distinct mood states. 
Regarding the characteristics of mental illness representations, as previously described in Di Mattei et al. [16], the statistical analyses show that patients within our sample reported a relatively weak illness Identity: the mean number of symptoms women associated to their disease was in fact rather low. With regard to patients' opinions surrounding their illness, the highest mean scores were found on the Emotional representations and the Treatment control subscales of the questionnaire. High scores on the first dimension indicate a response to illness characterized prevalently by negative emotions, reflecting intense emotional reactions that a disease, such as cancer, can invoke. Elevated scores on the Treatment control subscale demonstrate patients' confidence and their perception of control over the treatment. With regard to the perception of the causal factors responsible for GTD, the highest mean score was associated to "chance/bad luck".

Regression analyses show how illness perception is a significant predictor of psychological distress: in particular, the Consequences subscale of the IPQ-R (controlling for age, time since diagnosis, and type of diagnosis) maintains a specific association with state anxiety reported by the patients in our sample. This result confirms what Gould et al. [36] found within their sample of 61 gynecological cancer patients. The authors highlighted how the belief in serious consequences of the tumor, together with the feeling of a lack of control over the disease and a poorly coherent representation of illness, all positively correlate with the total score obtained on the Profile of Mood States Questionnaire. In a later study [37] on a larger sample of patients with gastrointestinal tract tumors, the authors underscored how the reception of negative consequences of the disease are significantly associated with anxiety and depression levels reported by the subjects on the Hospital Anxiety and Depression Scale. In light of these results, it is therefore possible to hypothesize that negative illness perception of GTD (believing GTD is a disease with severe consequences) could promote the representation of the pathology as being a serious threat and thus may result in higher levels of anxiety/ tension with regard to the contingent situation. It is nonetheless important to specify that the association between the Consequences subscale of the IPQ- $R$ and state anxiety could be an indirect relationship, mediated by other variables, such as coping strategies implemented by patients. The CSM does indeed postulate the presence of a causal relationship between mental illness representations and the use of certain coping mechanisms, which could in turn influence the outcome of the disease in terms of physical and psychosocial wellbeing [12]. To support these theoretical formulations Carlisle and colleagues [38] conducted a study on 125 women suffering from rheumatoid arthritis and they found that a coping style oriented towards avoidance (avoidant and resigned coping) represents the most significant mediator in the relationship between illness perception (especially Identity) and the level of disability and psychiatric morbidity developed by patients in response to illness. Gould et al. [36] confirm the significant role of coping styles, highlighting how denial and disengagement coping mechanisms mediate the impact of the representation of illness (particularly Timeline cyclical and Illness coherence) on mood in their sample. Thus, the advanced theoretical hypotheses of the CSM, together with the empirical studies cited above, suggest that coping mechanisms could act as significant mediators of the relationship between GTD mental representa- 
tions and the degree of psychological adaptation of the patients suffering from these disorders.

It is important to specify that the results of the present study do not confirm the significant relationship between illness perception dimensions and depressive mood reported from the above-mentioned studies [36] [37]. A possible explanation could be associated with the fact that the GTD patients in our sample are all well informed about the excellent survival rates resulting from the treatment of this condition, even in the case of malignant tumors. The perception of the high curability of their disease could weaken the sense of death threat generally evoked from a cancer diagnosis preventing them from developing persistent and severe feelings of sadness, hopelessness, worthlessness, and pessimism investigated by the Beck Depression Inventory.

The results of the present study also highlight how mental representations of illness can play a significant role in predicting infertility-related stress. Specifically, the regression analyses show that the Treatment control subscale of the IPQ- $R$ is negatively associated to Social concerns referred to infertility-related stress. Although in the literature no study has thus far investigated the relationship between illness perception and infertility-related stress, there are several reasons that could explain the result that emerged in our research. It is possible to hypothesize that the higher the confidence a patient has in treatment efficacy, the higher the confidence in a full recovery where reproductive abilities are not compromised [3]. The women in our sample seem to have a realistic vision of the current impossibility to conceive, which is only a temporary condition (for at least $6-12$ months in order to prevent the risk of relapse). This could promote a more functional psychosocial adaptation to disease, specifically in terms of a lower tendency to perceive feelings of discomfort and alienation from family and social contexts, resulting from infertility-related problems.

The generalizability of our results is limited due to the fact that our sample was mostly made up of Caucasian women with a medium-high education level. Another study limitation concerns the cross-sectional design; a measurement at only one point in time is limiting and it would be interesting to analyze possible changes in illness perception longitudinally in order to investigate causal relationships between the variables. Lastly, the study did not necessarily have a sufficiently large sample size $(\mathrm{N}=$ 37) to detect subtle differences, however, given the rarity of GTD and the choice not to use a tumor registry, the study is still considered pertinent and important in this field of research.

\section{Conclusions}

The present research is the first study to systematically investigate the relationship between illness perception and individual psychological adjustment in GTD patients.

The results of our study highlight how the belief in severe consequences of GTD significantly predicts the level of anxiety patients reported at the time of questionnaire completion, independently of other demographic and clinical variables. The present research also provides evidence of a specific impact of illness perception on infertilityrelated stress, showing that the perception of control over the treatment results in a lower score on the Social concern scale of the FPI. 
From a clinical point of view, the results of this study highlight the need to incentivize multidisciplinary support programs that aim to promote overall well-being [39]. In particular, this research underlines the importance of considering patient illness perception in the planning of support interventions. This variable seems to take on an important role in psychological adaptation to GTD, exercising a significant effect on both anxiety and infertility-related stress. It would therefore be desirable to promote psycho-educational programs intended to favor an accurate and adaptive illness perception as well as the acquisition of awareness of the generally favorable prognosis associated to GTD. Indeed, Paschali and colleagues [40] demonstrated that the communication of specific information, in accordance with subjective mental illness representations, fostered the modification of possible distorted beliefs and unrealistic expectations, thus contributing to a more accurate comprehension of the condition, as well as to a good level of psychological adaptation.

It is nevertheless necessary to replicate this study, especially in a longitudinal manner so as to observe changes in illness perception over time. Lastly, it would be interesting in future studies to evaluate patients' coping strategies as these have been found to mediate the relationship between illness perception and psychological adjustment to disease [36] [38]. The assessment of individual coping styles could help to enhance the understanding of the specific association between mental illness representations and psychological morbidity.

\section{References}

[1] Mangili, G., Lorusso, D., Brown, J., Pfisterer, J., et al. (2014) Trophoblastic Disease Guidelines of Diagnosis and Management. A Joint Report from the International Society for the Study of Trophoblastic Disease, European Organisation for the Treatment of Trophoblastic Disease, and the Gynecologic Cancer InterGroup. International Journal of Gynecolgical Cancer, 9, 109-116. https://doi.org/10.1097/IGC.0000000000000294

[2] Parazzini, F., Ricci, E., Cipriani, S., Bulfoni, G., Mangili, G. and Chiaffarino, F. (2012) Temporal Trends in the Frequency of Hydatidiform Mole in Lombardy, Northern Italy, 1996-2008. International Journal of Gynecological Cancer, 22, 318-322. https://doi.org/10.1097/IGC.0b013e31823b3504

[3] Goldstein, D.P. and Berkowitz, R.S. (2012) Current Management of Gestational Trophoblastic Neoplasia. Hematology Oncology Clinics of North America, 26, 111-131. https://doi.org/10.1016/j.hoc.2011.10.007

[4] Lurain, J.R. (2010) Gestational Trophoblastic Disease I: Epidemiology, Pathology, Clinical Presentation and Diagnosis of Gestational Trophoblastic Disease, and Management of Hydatidiform Mole. American Journal of Obstetrics and Gynecology, 203, 531-539. https://doi.org/10.1016/j.ajog.2010.06.073

[5] Wenzel, L.B., Berkowitz, R.S., Robinson, S., Goldstein, D.P. and Bernstein, M.R. (1994) Psychological, Social and Sexual Effects of Gestational Trophoblastic Disease on Patients and Their Partners. Journal of Reproductive Medicine, 39, 163-167.

[6] Horowitz, N.S. and Wenzel, L.B. (2009) Psychosocial Consequences of Gestational Trophoblastic Disease. In: Hancock, B.W., Seckl, M.J., Berkowitz, R.S. and Cole, L.A., Eds., Gestational Trophoblastic Disease, 3rd Edition, Wiley, Sheffield, 460-469.

[7] Di Mattei, V.E., Carnelli, L., Ambrosi, A., Mangili, G., Candiani, M. and Sarno, L. (2014) Gestational Trophoblastic Disease: Psychological Aspects and Fertility Issues. The Journal of Reproductive Medicine, 59, 488-495. 
[8] Di Mattei, V.E., Carnelli, L., Bernardi, M., Pagani Bagliacca, E., Zucchi, P., Lavezzari, L. and Sarno, L. (2015) An Investigative Study into Psychological and Fertility Sequelae of Gestational Trophoblastic Disease: The Impact on Patients' Perceived Fertility, Anxiety and Depression. PloS ONE, 10, e0128354. https://doi.org/10.1371/journal.pone.0128354

[9] Wenzel, L., Berkowitz, R.S., Habbal, R., Newlands, E., Hancock, B., Goldstein, D.P., Seckl, M., Bernstein, M., Strickland, S. and Higgins, J. (2004) Predictors of Quality of Life among Long-Term Survivors of Gestational Trophoblastic Disease. The Journal of Reproductive Medicine, 49, 589-594.

[10] Hagger, M.S. and Orbell, S. (2003) A Meta-Analytic Review of the Common-Sense Model of Illness Representations. Psychology \& Health, 18, 141-184. https://doi.org/10.1080/088704403100081321

[11] Jørgensen, I.L., Frederiksen, K., Boesen, E., Elsass, P. and Johansen, C. (2009) An Exploratory Study of Associations between Illness Perceptions and Adjustment and Changes after Psychosocial Rehabilitation in Survivors of Breast Cancer. Acta Oncologica, 48, 1119-1127. https://doi.org/10.3109/02841860903033922

[12] Leventhal, H., Meyer, D. and Nerenz, D.R. (1980) The Common Sense Representation of Illness Danger. In: Rachman, S., Ed., Contributions to Medical Psychology, Pergamon Press, New York, 17-30.

[13] Leventhal, H., Nerenz, D.R. and Steele, D.J. (1984) Illness Representations and Coping with Health Threats. In: Baum, A., Taylor, S.E. and Singer, J.E. Eds., Handbook of Psychology and Health, Volume IV: Social Psychological Aspects of Health, Erlbaum, Hillsdale, NJ, 219-252.

[14] Llewellyn, C.D., McGurk, M. and Weinman, J. (2007) Illness and Treatment Beliefs in Head and Neck Cancer: Is Leventhal's Common Sense Model a Useful Framework for Determining Changes in Outcomes over Time? Journal of Psychosomatic Research, 63, 17-26. https://doi.org/10.1016/j.jpsychores.2007.01.013

[15] Hopman, P. and Rijken, M. (2014) Illness Perceptions of Cancer Patients: Relationships with Illness Characteristics and Coping. Psycho-Oncology, 24, 11-18. https://doi.org/10.1002/pon.3591

[16] Di Mattei, V.E., Carnelli, L., Mazzetti, M., Bernardi, M., Di Pierro, R., Bergamini, A., Mangili, G., Candiani, M. and Sarno, L. (2016) Mental Representation of Illness in Patients with Gestational Trophoblastic Disease: How Do Patients Perceive Their Condition? PLoS ONE, 11, e0153869. https://doi.org/10.1371/journal.pone.0153869

[17] Giardini, A., Majani, G., Pierobon, A., Gremigni, P. and Catapano, I. (2007) Contribution to the Italian Validation of the IPQ-R. Giornaleitaliano di Medicina del Lavoroed Ergonomia, 29, A64-A74.

[18] Moss-Morris, R., Weinman, J., Petrie, K.J., Horne, R., Cameron, L.D. and Buick, D. (2002) The Revised Illness Perception Questionnaire (IPQ-R). Psychology \& Health, 17, 1-16. https://doi.org/10.1080/08870440290001494

[19] Beck, A.T., Ward, C.H., Mendelson, M., Mock, J. and Erbaugh, J. (1961) An Inventory for Measuring Depression. Archives of General Psychiatry, 4, 561-571.

https://doi.org/10.1001/archpsyc.1961.01710120031004

[20] Beck, A.T. and Steer, R.A. (1993) Beck Depression Inventory Manual. Psychological Corporation, San Antonio.

[21] Scilligo, P.F. (1988) La scala di depressione di Beck. In: Scilligo, P. F., Ed., Scale psicologiche 1. Stili, Coppia, Depressione, Amore, Narcisismo, IFREP, Roma.

[22] Furlanetto, L.M., Mendlowicz, M.V. and Bueno, J.R. (2005) The Validity of the Beck Depression Inventory-Short Form as a Screening and Diagnostic Instrument for Moderate and Severe Depression in Medical Inpatients. Journal of Affective Disorders, 86, 87-91. 
https://doi.org/10.1016/j.jad.2004.12.011

[23] Del Corno, F. and Lang, M. (2009) La diagnositestologica: Test neuropsicologici, test d'intelligenza, test di personalità, testing compterizzato. Francoangeli, Milano.

[24] Pedrabissi, L. and Santinello, M. (1989) STAI State-Trait Anxiety Inventory Forma Y Manuale. Organizzazioni Speciali, Firenze.

[25] Spielberger, C.D., Gorsuch, R.C. and Lushene, R.E. (1970) Manual for the State-Trait Anxiety Inventory. Consulting Psychologists Press, Palo Alto.

[26] Den Oudsten, B.L., Van Heck, G.L., Van der Steeg, A.F., Roukema, J.A. and De Vries, J. (2009) Predictors of Depressive Symptoms 12 Months after Surgical Treatment of EarlyStage Breast Cancer. Psycho-Oncology, 18, 1230-1237. https://doi.org/10.1002/pon.1518

[27] McQuellon, R., Wells, M., Hoffman, S., Craven, B., Russell, G., Cruz, J., et al. (1998) Reducing Distress in Cancer Patients with an Orientation Program. Psycho-Oncology, 7, 207 217. https://doi.org/10.1002/(SICI)1099-1611(199805/06)7:3<207::AID-PON304>3.0.CO;2-T

[28] Ambrosino, A. and Zurlo, M.C. (2011) La valutazione di dimensioni dello stress, risorse adattive e disagio emozionale in coppie infertili. Doctoral Dissertation, Università degli Studi di Napoli Federico II, Napoli, Italy. http://www.fedoa.unina.it/id/eprint/9022

[29] Newton, C.R., Sherrard, M.A. and Glavac, I. (1999) The Fertility Problem Inventory: Measuring Perceived Infertility-Related Stress. Fertility and Sterility, 72, 54-62. https://doi.org/10.1016/S0015-0282(99)00164-8

[30] Peterson, B.D., Newton, C.R. and Feingold, T. (2007) Anxiety and Sexual Stress in Men and Women Undergoing Infertility Treatment. Fertility and Sterility, 88, 911-914. https://doi.org/10.1016/j.fertnstert.2006.12.023

[31] IBM Corp (2013) IBM SPSS Statistics for Windows (Version 22.0). IBM Corp, Armonk.

[32] Wenzel, L.B., Berkowitz, R.S., Robinson, S., Bernstein, M.R. and Goldstein, D.P. (1992) The Psychological, Social and Sexual Consequences of Gestational Trophoblastic Disease. Gynecologic Oncology, 46, 74-81. https://doi.org/10.1016/0090-8258(92)90200-3

[33] Ferreira, E.G., Maestá, I., Michelin, O.C., de Paula, R.C., Consonni, M. and Rudge, M.V. (2009) Assessment of Quality of Life and Psychologic Aspects in Patients with Gestational Trophoblastic Disease. The Journal of Reproductive Medicine, 54, 239-244.

[34] Walsh, J.C., Lynch, M., Murphy, A.W. and Daly, K. (2004) Factors Influencing the Decision to Seek Treatment for Symptoms of Acute Myocardial Infarction: An Evaluation of the Self-Regulatory Model of Illness Behaviour. Journal of Psychosomatic Research, 56, 67-73. https://doi.org/10.1016/S0022-3999(03)00082-5

[35] Millar, K., Purushotham, A., McLatchie, E., George, W.D. and Murray, G.D. (2005) A 1-Year Prospective Study of Individual Variation in Distress, and Illness Perceptions, after Treatment for Breast Cancer. Journal of Psychosomatic Research, 58, 335-342. https://doi.org/10.1016/j.jpsychores.2004.10.005

[36] Gould, R.V., Brown, S.L. and Bramwell, R. (2010) Psychological Adjustment to Gynaecological Cancer: Patients' Illness Representations, Coping Strategies and Mood Disturbance. Psychology \& Health, 25, 633-646. https://doi.org/10.1080/08870440902811163

[37] Dempster, M., McCorry, N.K., Brennan, E., Donnelly, M., Murray, L. and Johnston, B.T. (2012) Psychological Distress among Survivors of Esophageal Cancer: The Role of Illness Cognitions and Coping. Disease of the Esophagus, 25, 222-227. https://doi.org/10.1111/j.1442-2050.2011.01233.x

[38] Carlisle, A.C.S., John, A.M.H., Fife-Show, C. and Lloyd, M. (2005) The Self-Regulatory Model in Women with Rheumatoid Arthritis: Relationships between Illness Representations, Coping Strategies and Illness Outcome. British Journal of Health Psychology, 10, 571-587. https://doi.org/10.1348/135910705X52309 
[39] Di Mattei, V.E., Bisceglie, A.R., Sigismondi, C., Mangili, G., Prunas, A. and Sarno, L. (2010) Analisi della domanda e dei bisogni psicologici in un reparto di ginecologia oncologica. Psicologia della Salute, 3, 131-144.

[40] Paschali, A.A., Hadjulis, M., Papadimitriou, A. and Karademas, E.C. (2015) Patient and Physician Reports of the Information Provided about Illness and Treatment: What Matters for Patients' Adaptation to Cancer during Treatment? Psycho-Oncology, 24, 901-909. https://doi.org/10.1002/pon.3741

Submit or recommend next manuscript to SCIRP and we will provide best service for you:

Accepting pre-submission inquiries through Email, Facebook, LinkedIn, Twitter, etc. A wide selection of journals (inclusive of 9 subjects, more than 200 journals) Providing 24-hour high-quality service User-friendly online submission system Fair and swift peer-review system Efficient typesetting and proofreading procedure Display of the result of downloads and visits, as well as the number of cited articles Maximum dissemination of your research work

Submit your manuscript at: http://papersubmission.scirp.org/ Or contact ojmp@scirp.org 